\title{
Antagonistic activity of probiotic organism against Vibrio cholerae and Cryptococcus neoformans
}

\author{
Vidya, R. and lyer, P. R. \\ Women`s Christian College, College Road, Chennai-600006. \\ E-mail: brajuraj@yahoo.com \\ Received 27 November 2008; received in revised form 21 July 2009; accepted 31 July 2009
}

\begin{abstract}
The microbes are useful in many ways in the modern world. Probiotics one of them, which refers to, acid adherence bacteria in the intestinal cells, are able to survive at low $\mathrm{pH}$ and produce large amount of lactic acid. The present investigation deals with the antagonistic activity of Lactobacillus acidophilus organism against pathogens. The organism was isolated from the curd sample. Identification of bacteria was done by various biochemical testing. The present study revealed that L. acidophilus inhibits Vibrio cholerae more efficiently than Streptococcus pneumoniae and Shigella dysentriae. When $L$. acidophilus and $V$. cholerae were grown together, $L$. acidophilus dominated the growth and competitively inhibited the growth of $V$. cholerae. L. acidophilus was also found to inhibit Cryptococcus neoformans.
\end{abstract}

Keywords: Probiotics, acid adherence bacteria, lactic acid bacteria

\section{INTRODUCTION}

'Probiotics' are live microbial food and feed supplements that are supposed to benefit health by improving the balance of the intestinal microbial community. The term probiotics was first introduced by Parker (1974). According to him probiotics are "Organisms and substances which contribute to intestinal microbial ecological balance". Helpful bacteria, such as $L$. acidophilus and $B$. bifidum, have the ability to kill off other bacteria by secreting small quantities of antibiotic-like substances, including lactic-acid, acetic-acid, benzoicacid, hydrogen peroxide, acidolin, lactocidin and acidophilin. Research has shown that the benefits of the friendly bacteria are achieved without the undesirable side effects of antibiotic therapy, including diarrhea, digestive problems and vaginal yeast infections (Fuller, 1989).

Lactobacilli of human intestinal origin have been shown to exhibit antagonistic activity against both Gram positive and Gram negative bacteria. Many strains belonging to the $L$. acidophilus groups have been reported to produce antimicrobial compounds, which show a great variety as to their inhibition spectrum. Antimicrobial substance produced are smaller peptides and do not contribute to the formation of resistance to pathogens (Alla et al., 2003). Feed conservation rate is decreased due to the fact that many of the probiotic microorganisms produce enzymes like amylase, protease and lipase, whether in gut or in environment. The pathogens are kept at bay by probiotic microorganisms by the process called competitive inhibition (Akshat et al., 2004; Attai et al., 1987).

\section{${ }^{\star}$ Corresponding author}

\section{MATERIALS AND METHODS}

\section{Microscopic examination}

A loop full of curd was placed on clean glass slide. Cover slip was placed on it. The slide was observed under the microscope.

\section{Serial dilution}

The locally procured curd sample was homogenized and then it was serially diluted to all seven test tubes till $10^{-9}$

\section{Plating: spread plate method}

Rogosa Medium was used for the isolation and enumeration of Lactobacilli in the oral and intestinal microbial flora, meat, milk and other food stuffs. $0.1 \mathrm{~mL}$ of the serially diluted sample was spread plated on Rogosa Medium plates. The plates were incubated in Anareobic Gas Pack Jar for $48 \mathrm{~h}$ at $37^{\circ} \mathrm{C}$ (De Man et al., 1960).

\section{Identification of $L$. acidphilus (Harringan and Margaret, 1993)}

A control sample of the $L$. acidophilus was used. This culture was procured from the microbiology lab of the local Aavin dairy.

\section{Gram staining}

Gram staining was performed with the colonies obtained from the Rogosa Plate after incubation using Crystal Violet and Safranine stains. 


\section{Catalase test}

Catalase test was performed by transforming the bacterial culture to the slide containing hydrogen peroxide using glass rod. The slide was then examined for the formation of bubbles within few minutes.

\section{Motility test}

Motility test was performed using hanging drop method.

\section{Detection of carbon dioxide production from glucose}

Gibson's semi-solid medium was prepared and $\mathrm{pH}$ was adjusted to 6.5 and was distributed to test tubes to a depth of 5 to $6 \mathrm{~cm}$ and sterilized by steaming. Incubation was made with inoculation needle. The tubes were incubated in anaerobic jar for $48 \mathrm{~h}$ at $37^{\circ} \mathrm{C}$

\section{Detection of ammonia production from arginine}

Arginine MRS broth was prepared and distributed in tubes and sterilized at $15 \mathrm{lb}$ for $15 \mathrm{~min}$. The culture was inoculated and incubated in anaerobic jar for 7 days at $25{ }^{\circ} \mathrm{C}$. Nessler's reagent was added to detect the ammonia production.

\section{Fermentation tests}

MRS fermentation containing $0.004 \%$ chlorophenol red was prepared and distributed in tubes and sterilized at $15 \mathrm{lb}$ for $15 \mathrm{~min}$. $10 \%$ of test substrate (Mannitol) was prepared, sterilized (filtration) and was aseptically added to the sterilized MRS broth to give a final concentration of $2 \%$.Culture was inoculated and incubated in Anaerobic Jar for 3 days.

\section{Antibacterial assay}

Bacterial cultures of $V$. cholerae, $S$. pneumoniae and $S$. dysentriae were obtained from the Microbiology labs of a Private Laboratory, Chennai. Aspergillus niger and $C$. neoformans was procured from IMTECH, Chandigarh, INDIA.

\section{Well assay}

Muller Hinton agar plates were prepared surface of the MHA plates was inoculated with the swab containing $24 \mathrm{~h}$ culture ( $V$. cholerae). Wells were punched with the gel puncher $20 \mathrm{~mL}$ of supernatant of culture (L. acidophilus) were added to the wells punched in the centre of the plates. Plates were incubated for $24 \mathrm{~h}$ at $37^{\circ} \mathrm{C}$. S pneumoniae and $S$. dysentriae were also incubated on the MHA plates, separately and wells were punched as mentioned above.

\section{Well assay using solvents}

A $24 \mathrm{~h}$ culture of $L$. acidophilus from MRS broth were taken $(3 \mathrm{~mL}$ ) in eppendorf and centrifuged at 10,000 rpm for $15 \mathrm{~min}$. Supernatant were collected separately and to equal amounts of solvents like butanol, chloroform, propanol, methanol, acetone, isoamylalcohol, diethyl ether, petroleum ether and hexane was added in separate eppendorf. Solvents were allowed to evaporate and the sample $(30 \mu \mathrm{L})$ was added to the well punched in the plates. Plates were incubated for $24 \mathrm{~h}$ at $37^{\circ} \mathrm{C}$.

\section{Colony inhibition}

Hundred microlitre of $V$. cholerae culture was added to first tube containing nutrient broth. $100 \mathrm{~mL}$ of sample culture was added to second tube containing nutrient broth.

Hundred microlitre of $V$. cholerae was added to the third tube containing nutrient broth. To the same tube 100 $\mathrm{mL}$ of sample culture was added. All the three tubes were kept for overnight incubation. Each tube was serially diluted to $10^{-7}$ tube. V. cholerae was serially diluted and spread plated on TCBS agar.

Serial dilution performed with sample culture was spread plated in MRS agar plate.

The mixture ( $V$. cholerae with sample) which was serially diluted was placed both on MRS agar and TCBS agar plates. The plates were incubated at $37^{\circ} \mathrm{C}$ for $24 \mathrm{~h}$.

\section{Mycological methods}

\section{Preparation of culture filtrate}

Twenty four hours culture (sample) was centrifuged at $15,000 \mathrm{rpm}$ for $10 \mathrm{~min}$. Sterile cell-free supernatant was suspended in $10 \mathrm{mM}$ acetic acid.

\section{Fungal inocula}

Inocula containing spores or conidia were prepared by growing the molds on PDA slants for 7 days. Spores or conidia were collected after vigorously shaking the slants with sterile peptone water. $24 \mathrm{~h}$ yeast cell inocula were prepared from washed cultures grown in PDA broth at $30{ }^{\circ} \mathrm{C}$.

\section{Antifungal activity assays}

\section{Agar- diffusion assay}

MRS agar plates containing $A$. niger conidia and $C$. neoformans were prepared. Wells, with a diameter of $5 \mathrm{~mm}$, were then cut in the agar using sterile gel puncher. $30 \mu \mathrm{L}$ of samples were added to each well and allowed to diffuse into the agar during a $5 \mathrm{~h}$ preincubation period at room temperature, followed by aerobic incubation at $30^{\circ} \mathrm{C}$ (Muriana and Klaenhammer, 1991; Magnusson and Schnürer, 2002). 


\section{Overlay method}

Overlay method was performed using MRS agar plates on which $L$. acidophilus were inoculated as two (2) cm-long lines. Inoculated plates were incubated at $30^{\circ} \mathrm{C}$ for $48 \mathrm{~h}$ in Anaerobic jar. The plates were then overlaid with $10 \mathrm{~mL}$ of Potato Dextrose Soft agar containing yeast cells or fungal spores (conidia). The plates were then incubated aerobically at $30{ }^{\circ} \mathrm{C}$ for $48 \mathrm{~h}$. The plates were examined for clear zones of inhibition around the bacterial streaks (Jacobsen et al., 1999; Sjögren et al., 2003).

\section{RESULTS}

L. acidophilus was isolated on Rogosa media from curd sample. The organism is identified as $L$. acidophilus based on the Bergey's Manual of Bacteriology and the control organism results ( $8^{\text {th }}$ Edition) (Table 1$)$.

\section{Antibacterial assay}

Well assay

The inhibitory activity against $V$. cholerae, S. pneumoniae and $S$. dysentriae was seen in (Figure 1,2 and 3 and Table 2) zone of clearance obtained with each organism (Piard and Desmazeaud, 1992; Ogunbanwo et al., 2003).

\section{Well assay using solvents}

The inhibitory activity against $V$. cholerae, $S$. pneumoniae and $S$. dysentriae using solvents such as acetone, butanol chloroform, propanol, methanol, isoamyl alcohol, diethyl ether, petroleum ether and hexane was observed (Figure 4,5 and 6 and Table 3) as zone of inhibition obtained with each organism.

\section{Colony inhibition}

The colony inhibitory effect of Lactobacillus on $V$. cholerae on TCBS agar plate is shown in (Figure 7 and 8 and Table 4) shows total number of colonies obtained in $10^{-4}$ and 10 6 dilution (Klaenhammer, 1983; Kastmoglu and Akgun, 2004; Alkaline et al., 2004).

\section{DISCUSSION}

The result obtained for antimicrobial activity using well assay inferred Lactobacillus acidophilus inhibits $V$. cholerae, $S$. dysentriae and $S$. pneumoniae. It could be seen from the Table 1 that of the three bacteria used for antibacterial activity of $L$. acidophilus, $V$. cholerae was found to be the most sensitive. Similar results have been reported for Lactobacillus sp. (Juven et al., 1992). Lactobacillus sp. of organism has also been reported to be active against the vaginal pathogens. The results also prove the natural medicine correct where buttermilk is used for diarrhea (Piard and Desmazeaud, 1992).
Table 1: Biochemical characteristics of Lactobacillus acidophilus

\begin{tabular}{cll}
\hline SI. No & \multicolumn{1}{c}{ Test } & L. acidophilus \\
\hline 1. & Grams Reaction & Positive \\
2. & Catalase test & Negative \\
3. & Motility test & Non.motile \\
4. & Gas from Glucose & Negative \\
5. & Arginine test & Negative \\
6. & Mannitol & Negative \\
7. & Lactose & Positive \\
8. & Glucose & Positive \\
\hline
\end{tabular}

Table 2: Overlay method to check antimicrobial activity

\begin{tabular}{ll}
\hline \multicolumn{1}{c}{ Organisms } & Zone of clearance \\
\hline Vibrio cholerae & $10 \mathrm{~mm}$ \\
Streptococcus pneumoniae & $3 \mathrm{~mm}$ \\
Shigella dysentriae & $8 \mathrm{~mm}$ \\
\hline
\end{tabular}

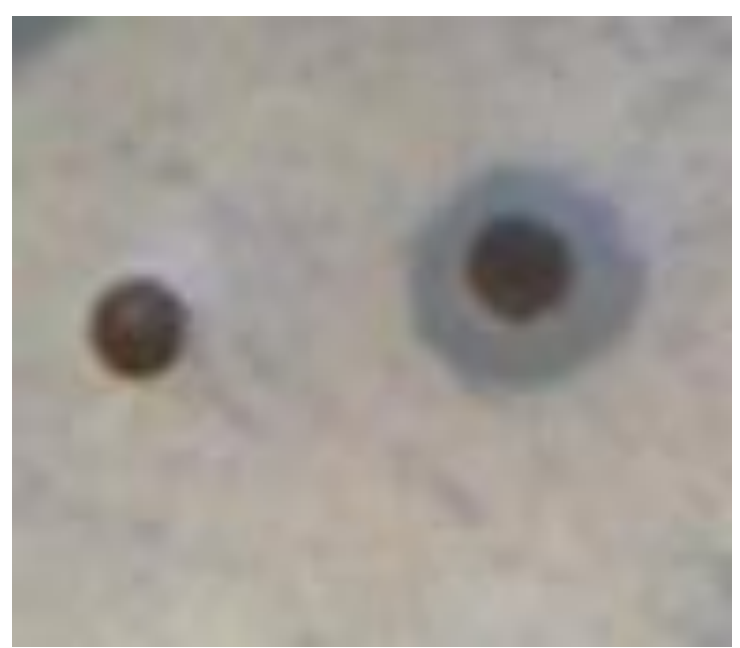

Figure 1: Zone of inhibition on Vibrio cholerae

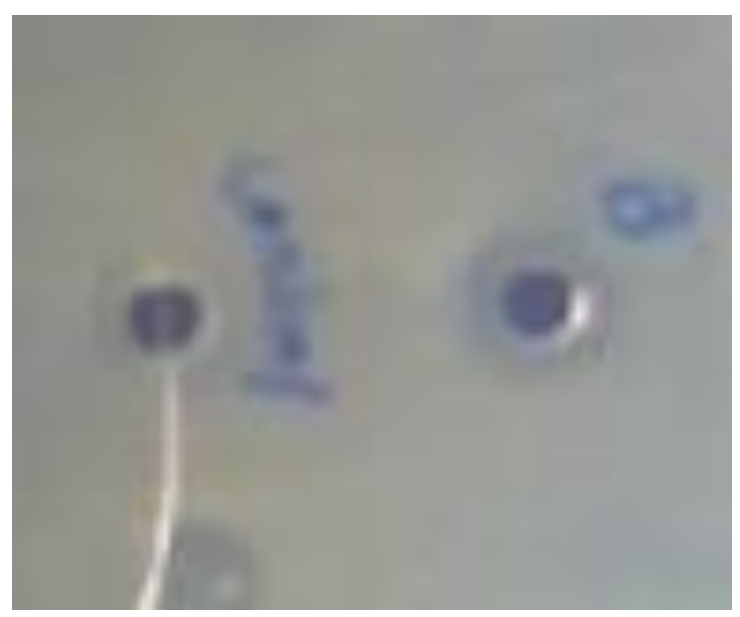

Figure 2: Zone of inhibition on Streptococcus pneumoniae 


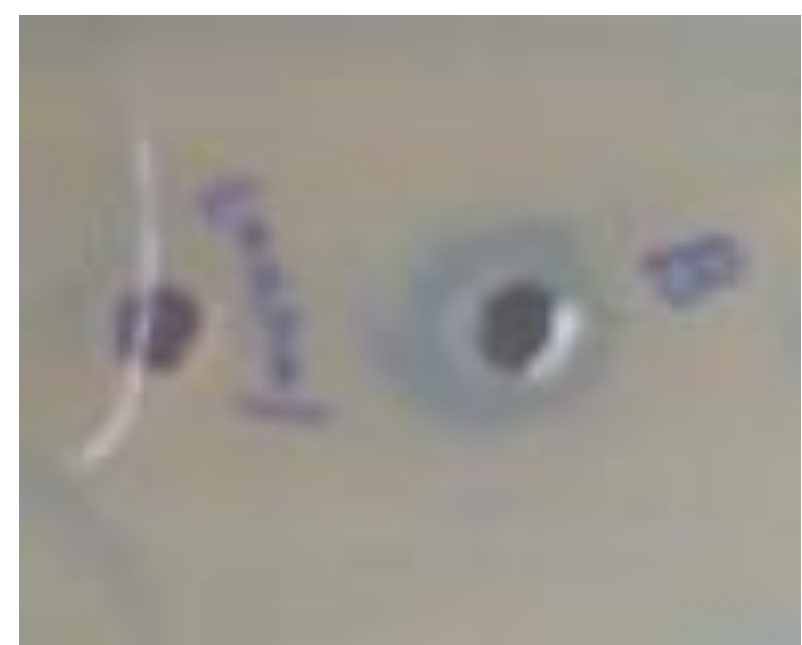

Figure 3: Zone of inhibition on Shigela dysentriae

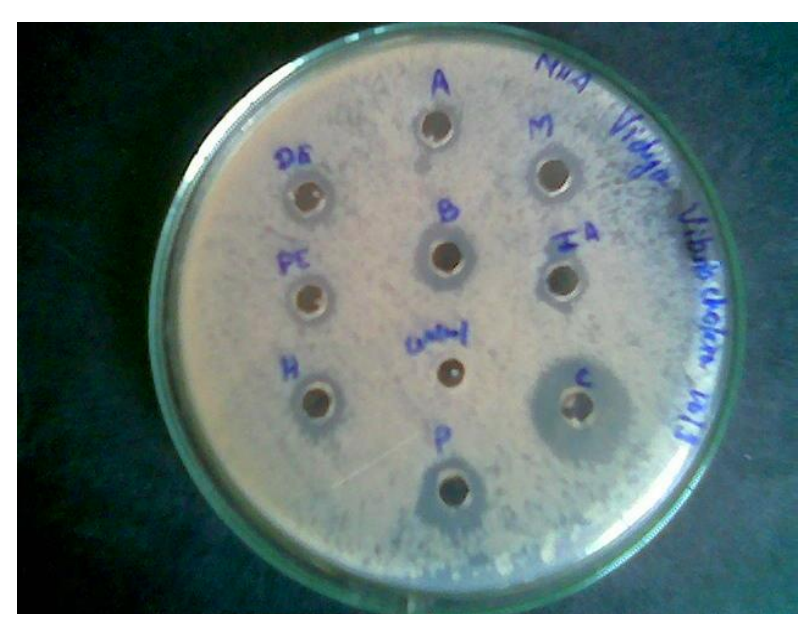

Figure 4: Zone of inhibition on Vibrio cholerae

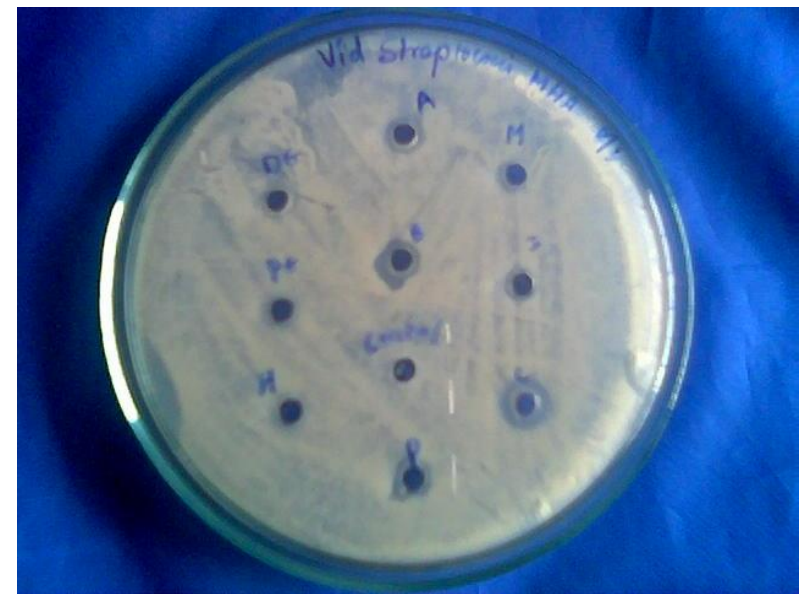

Figure 5: Zone of inhibition on Streptococcus pneumoniae

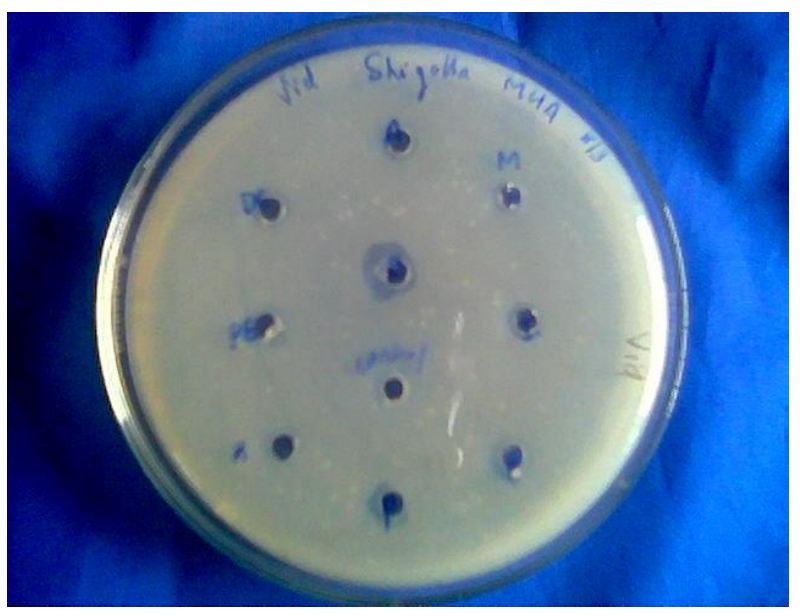

Figure 6: Zone of inhibition on Shigela dysentriae

Table 3: Well Assay using solvent extracts to check antimicrobial activity

\begin{tabular}{llc}
\hline Organisms & \multicolumn{1}{c}{ Solvents } & $\begin{array}{c}\text { Zone of } \\
\text { clearance }\end{array}$ \\
\hline Vibrio & Acetone & $10 \mathrm{~mm}$ \\
cholerae & Butanol & $10 \mathrm{~mm}$ \\
& Propanol & $9 \mathrm{~mm}$ \\
& Methanol & $9 \mathrm{~mm}$ \\
& Iso Amyl Alcohol & $10 \mathrm{~mm}$ \\
& Chloroform & $12 \mathrm{~mm}$ \\
& Hexane & $9 \mathrm{~mm}$ \\
Shigela & Petroleum Ether & $8 \mathrm{~mm}$ \\
dysentriae & Diethyl Ether & $8 \mathrm{~mm}$ \\
\cline { 2 - 2 } & Acetone & $2 \mathrm{~mm}$ \\
& Butanol & $10 \mathrm{~mm}$ \\
& Propanol & $5 \mathrm{~mm}$ \\
& Methanol & - \\
& Iso Amyl Alcohol & $2 \mathrm{~mm}$ \\
& Chloroform & - \\
& Hexane & - \\
& Petroleum Ether & - \\
& Diethyl Ether & $1 \mathrm{~mm}$ \\
\hline Streptococcus & Acetone & $1 \mathrm{~mm}$ \\
pneumoniae & Butanol & $2 \mathrm{~mm}$ \\
& Chloroform & $8 \mathrm{~mm}$ \\
& Propanol & $1 \mathrm{~mm}$ \\
& Methanol & $1 \mathrm{~mm}$ \\
& Iso Amyl Alcohol & $1 \mathrm{~mm}$ \\
& Hexane & - \\
& Petroleum Ether & - \\
& Diethyl Ether & - \\
\hline & &
\end{tabular}

Table 2 shows that of the solvents used, chloroform seems to be the best solvent in the extraction of antibacterial compound to prevent the growth of $V$. cholerae and $S$. pneumoniae whereas butanol was found to extract antibacterial compound efficiently to inhibit $S$. dysentriae. A control was tried where only solvent was 
Table 4: Colony inhibition

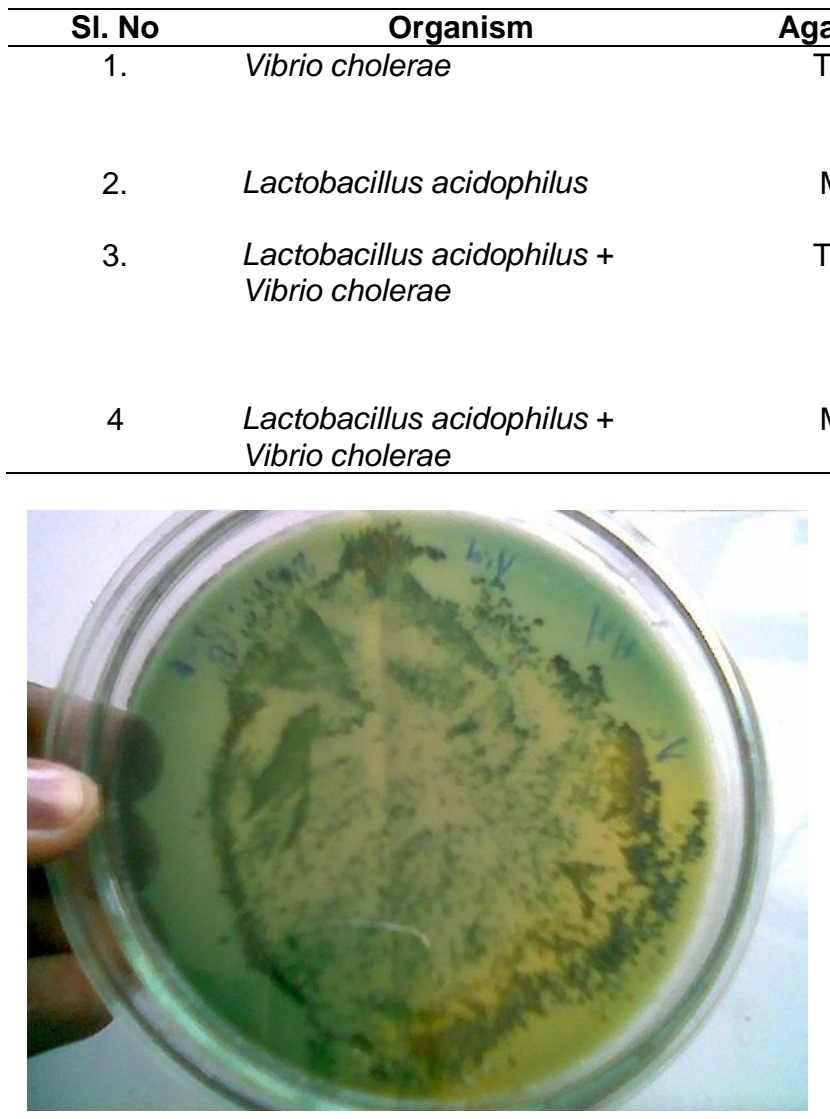

Figure 7: Vibrio cholerae on TCBS

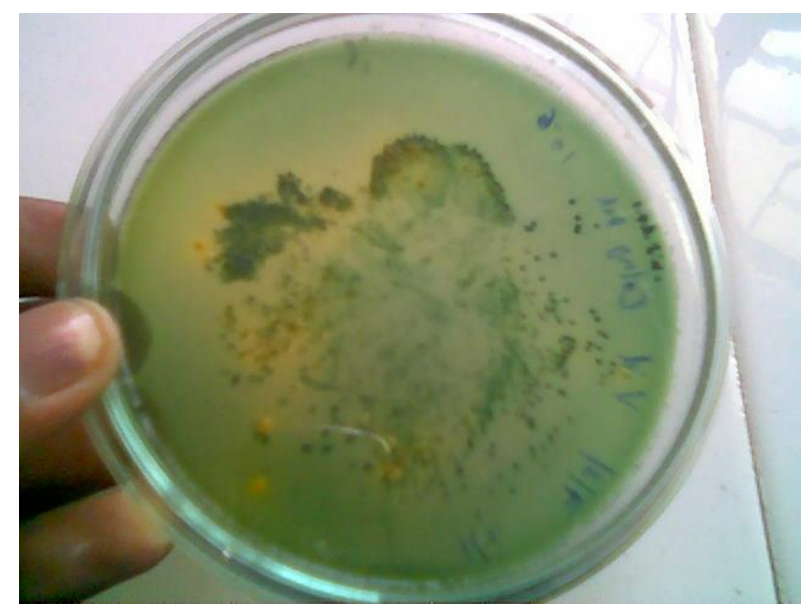

Figure 8: Mixed culture on TCBS

added to the wells to see if solvent caused the inhibition but solvent alone without the antimicrobial compound had no effect on the organisms (Muriana and Klaenhammer, 1991; Juven et al., 1992; Peant and Lapointe, 2004). $\begin{array}{lll}\text { MRS } & 10^{-4} & \text { Numerous to count }\end{array}$

The use of solvent caused better extraction of the antimicrobial in comparison to water extracts.

The growth of $V$. cholerae was much reduced in the presence of Lactobacillus. When the growth of $V$. cholerae and $L$. acidophilus in nutrient broth is considered, both had more or less similar growth. When the growth together is seen, $L$. acidophilus dominated the growth. This result clearly shows that competitively inhibits the growth of $V$. cholerae. The presence of Lactobacillus was sufficient for the inhibition of growth of $V$. cholerae (Malinen and Bigret, 1998; Miller et al., 2001; Corcoran et al., 2004).

These results indicate the ability of the antimicrobial produced by $L$. acidophilus against the pathogen but its ability to grow with normal flora is also clearly observed (Reddy et al., 1984).

$L$. acidophilus also showed antifungal activity. It inhibited the growth of $C$. neoformans. But no inhibition was observed against $A$. niger. This could be because the antifungal compound produced by the $L$. acidophilus could be specific in inhibiting $C$. neoformans but not $A$. niger (Jacobsen et al., 1999; Magnusson and Schnürer, 2002; Kastmoglu and Akgun 2004).

\section{CONCLUSIONS}

The curd sample was used to isolate the L. acidophilus organism. The organism was tested for antibacterial activity against Gram positive and Gram negative organism (S. pneumoniae, V. cholerae and S. dysentriae) using well assay and also using solvents to extract the antibacterial compounds. Inhibition of $V$. cholerae was done by $L$. acidophilus by the colony inhibition method. The organism was tested for antifungal activity against $A$. niger and $C$. neoformans by overlay method and agar diffusion method. The work will be useful to understand the importance of probiotics against pathogenic organisms.

\section{REFERENCES}

Akshat, T., Kailasapathy, K., Arumugasamy, R., Nguyen, M., and Reynolds, N. (2004). Enhancement of oxygen tolerance of probiotic in dairy 
foods. Proceeding of $11^{\text {th }}$ World Congress of Food Science and Technology pp. 172-184.

Alla, A., Aroutcheva, Jose., Simoe, A., and Faro, S., (2003). Antimicrobial protein produced by vaginal Lactobacillus acidophilus that inhibits Gardenella vaginalis Parthenon Publishing 9, 33-39.

Attai, R., Whalen, P. J., Shahani, K. M. and Amer, M. A. (1987). Inhibition of growth of Staphylococcus aureus during production of acidophilus yoghurt. Journal of Food Protection 50, 224-228.

Kastmoglu, A. and Akgun, S. (2004). Survival of Escherichia Coil 0157: H7 in the processing and post processing stages of acidophilus yoghurt. International Journal of Food Science and Technology 39, 556-568.

Akaline, A. S., Fenderya, S. and Akbulut, N. (2004). Viability and activity of bifidobacteria in refrigerated storage. International Journal of Food Science and Technology 39, 613-621.

Klaenhammer, T. K. (1983). Detection and activity of lactacin B a bacteriocin produced by Lactobacillus acidophilus. Applied Environmental Microbiology 45, 1808-1815.

Corcoran, B. M., Ross, R. P., Fitzgerold, G. F. and Stanton, C. (2004). Comparative survival of probiotic Lactobacilli spray-dried in the presence of prebiotic substances. Journal of Applied Microbiology 96, 1024-1039.

De Man, J. C., Rogosa, M. and Sharpe, M. E. (1960). A medium for the cultivation of Lactobacilli. Journal of Applied Bacteriology 23, 130-135.

Fuller, R. (1989). A review, probiotics in man and animals. Journal of Applied Bacteriology 66, 365-378.

Harringan, W. F. and Mc Cance. M. E. (1993) Laboratory Methods in Microbiology. Academic Press Harcourt Brace and Company Publishers. pp.164-230.

Jacobsen, C. N., Rosenfeldt, V., Nielsen, A. E., Ford, H., Moller, P. L., Michaelsen, K. F., Aerregaard, A. P., Sandstrom, B., Tvede, M. and Jakobsen, M. (1999). Screening of probiotic Activities of forty seven strains of Lactobacillus Spp by Invitro Techniques and Evaluation of the colonization ability of five selected strains in Humans. Applied and Environmental Microbiology 65, 4949-4956.

Magnusson, J. and Schnürer, J. (2002) Lactobacillus coryniformis subsp. Coryniformis strain $\mathrm{Si} 3$ produces a broad-Spectrum proteinaceous antifungal Compound. Journal of Applied Environmental Microbiology 67, 1-5.

Sjögren, J., Magnusson, J., Broberg, A., Schnürer, J. and Kenne, L. (2003) Antifungal 3-Hydroxy Fatty Acids from Lactobacillus plantarum MiLAB 14. Journal of Applied Environmental Microbiology 12, 7554-7557.

Juven, B.J., Schved, F. and Lindner, P. (1992). Antagonistic compounds produced by a chicken intestinal strain of Lactobacillus acidophilus. Journal of Food Protection 55, 157-161.
Mayra - Malinen, A. and Bigret, M. (1998). Industrial use and production of lactic acid bacteria. A. Salmein and .A von Wright Publicationns.pp. 73-102.

Miller, C. W., Nguyen, M., Rooney, M., Kaillsapathy, K. and Davies, K. (2001). Enhancement of the Viability of probiotic bacteria by novel packaging technology. Proceedings of the $10^{\text {th }}$ World Congress of Food Science and Technology. pp. 182-187.

Muriana, P. M. and Klaenhammer, T. R. (1991). Purification and partial characterization of Lactocin $\mathrm{F}$, a produced by Lactobacillus acidophilus. 11088 . Applied and Environmental Microbiology 57, 114-121.

Ogunbanwo, S. T., Sanni, A. I. and Onilude, A. A. (2003). Characterization of bacteriocin produced by Lactobacillus plantarum $\mathrm{F} 1$ and Lactobacillus brevis OGL. African Journal of Biotechnology 2, 219-227.

Peant, B. and Lapointe, G. (2004). Identification of characterization of a conserved nuclease secreted by strains of the Lactobacillus casei group. Journal of Applied Microbiology 96, 367-374.

Piard, J. C. and Desmazeaud, M. (1992). Inhibiting factors produced by lactic acid bacteria. Part $Z$. bacteriocins and other antibacterial substances. Lait 72, 113-142.

Quiberoni, A., Gudlielmotti, D., Binetti, A. and Reinheimer, J. (2004). Characterization of three Lactobacillus delbrueckii subsp bulgaricus Lactobacillus acidophilus and Lactobacillus bulgaricus, production and partial. Purification of bulgaricus cultured. Consejo Nacional De Investigaciones Cientifacs $\mathrm{Y}$ Technicas Blackwell Publishing. 96 pp.340-351

Reddy, G. C., Shahani, K. M., Friend, B. A. and Chandan, R. C. (1984). Natural antibiotic activity of Lactobacillus acidophilus and bulgaricus, production and parital. Purification of bulgaricus cultured. Journal of Dairy Products 8, 15-19. 